\title{
THE RADIO WARNING SERVICE FOR APPLE AND PEAR SCAB IN THE NETHERLANDS ${ }^{1}{ }^{2}$ )
}

\author{
C. A. R. MEIJNEKE \\ Plantenziektenkundige Dienst (Plant Protection Service), \\ Wageningen, Netherlands
}

\section{SUMMARY}

A survey is given of the radio warning service for apple and pear scab, in use in the Netherlands since 1948. The work is carried out by the Plant Protection Service in close cooperation with the Royal Dutch Meteorological Institute, the Horticultural Extension Service and several fruitgrowers.

It is based upon earlier Dutch research by VAN DE Pol, Vlasveld, Knoppien et al.

In the last four years there has been a considerable change in the set-up. The development of certain organo mercury spray compounds led to the possibility of spraying curatively. The findings of MiLls about infection periods of the scab fungus are now fully used.

\section{INTRODUCTION}

The radio scab warning service in the Netherlands has been in operation since 1948. It was started by the Plant Protection Service. From the beginning there has been a close collaboration with the Royal Dutch Meteorological Institute (K.N.M.I.). Since 1956 the Horticultural Extension Service (R.T.V.D.) has also taken part.

The warnings are incorporated in the daily weather talks given by the Meteorological Institute especially for agriculturalists and horticulturalists. During the growing season these talks are given three times a day on weekdays and once on Sundays. They are broadcast on weekdays at 5.45 and 6.40 in the morning and at 12.30 ; on Sundays only at 6.40 .

The radio-warnings about apple and pear scab (Venturia inaequalis (Cke.) Aderh. and V. pirina Aderh.) are based upon :

the development of the fungus,

the development of the trees,

the weather conditions.

At present only the period of ascospore release is covered. Usually the ascospore period begins towards the end of March or the beginning of April and ends in June. With the ending of the ascospore discharge the radio warnings are stopped also.

At present warnings are issued when :

a the ascospores are ready to mature. This is a prewarning;

$\mathrm{b}$ ascospores are expected to be released following rain. This is a second prewarning ;

c ascospore release has begun in the open;

d infection periods have occurred;

e ascospore discharge has ceased.

1) Received for publication September 7, 1957.

2) Paper given at the conference of Advisory Plant Pathologists, Ministry of Agriculture, Fisheries and Food, London, 29 February 1956. Revised August 1957. 
Only in the warnings $\mathbf{a}$ and $\mathbf{b}$ are remarks about the necessary sprays included. This is only possible then because of the uniformity of the advice that can be given at that time. Afterwards the spraying practice differs too much, so decisions about what to do after the radio warnings are then left entirely to the grower. The radio warning service is only meant to help the grower make his decision about what to do by giving him some of the facts he needs. It is not meant to dictate the measures he should take. The system assumes a good education of the growers so that they can interpret the warning. Moreover they are informed about the warning service and about the possible interpretations in technical weekly publications before the ascospore period starts.

\section{The DeVelopment of THE FUngus}

The fungus spreads in spring by means of conidia and ascospores. In the Netherlands the conidia may be - but are not always - released earlier, even much earlier than the ascospores, but initial infection by ascospores is of much more importance in the Netherlands than that by conidia. Early conidial infection is only of significance on some pear varieties and on one or two apple varieties (e.g. Cox's Orange Pippin). In well sprayed and well tended orchards this danger is not great.

Overwintering stromata have been found only in apple orchards which were not regularly sprayed (6). Consequently we do not generally spray earlier then shortly before the appearance of the first ascospores. Only those growers who know that they have twig infection in their orchards and so are liable to have early conidial infection give a very early spray. The growers get their information about the ripening of the ascospores and when to expect the first ascospores by the radio warnings.

The warnings $a, b, c$ and $e$ are based mainly upon the development of the ascospores, which is being followed centrally for the whole country at the Plant Protection Service in Wageningen in the centre of the country. Earlier research $(6,3,4,7)$ has shown that ascospore ripening is sufficiently simultaneous throughout the country to do so. Possible differences in the time of release of the first ascospores and of the last ones from leaves from different varieties and from early or late fallen leaves have also been investigated. Moreover there is a check each year on the findings at the Plant Protection Service by the research worker on apple and pear scab, RoosjE, at the Fruit Research Station in Wilhelminadorp in the south-west of the Netherlands. We never fail to find the first and the last ascospores on nearly the same day. Also there has been for several years a check in the north-east of the country with the same good accordance.

Based on the results of earlier research (4) the following practice has been adopted.

A lot of heavily infected leaves of different varieties from several orchards is gathered during the preceding winter or in early spring and a sample of them is taken daily into the laboratory and put in petridishes in an incubator. Laboratory-work is started early enough each year to be sure there is still no mature perithecium. In our experience we need to start in the second half of March.

The leaves are kept for three days in the incubator at a temperature of 
$26^{\circ} \mathrm{C}$ to accelerate the ripening of the perithecia. After these three days the leaves are wetted in the petridishes and slides are placed over them (fig. 1). After several hours the slides are examined for ascospores under a microscope or a binocular (fig. 2).

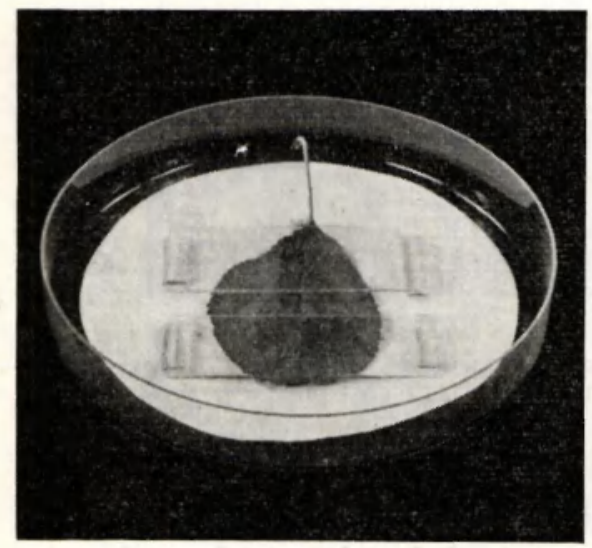

Fig. 1 Petri-dish With SCAB-INFECted LEAF AND SLIDES PUT OVER IT.

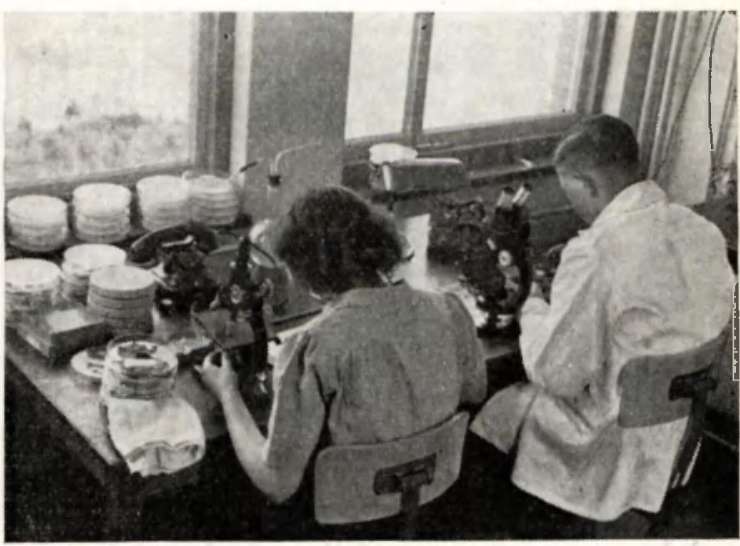

Fig. 2 EXaMINATION OF ASCOSPORE-EXPUL SION OF "ARTIFICIALIY ACCELERATED" LEAVES.

The stage of development of the perithecia is also observed under the microscope by determining the easiness of the release of ascospores from several perithecia by pressing upon them.

When ascospores are found on the slides over these artificially accelerated perithecia the first pre-warning (a) is broadcast. This warning is really a sort of prediction. The fruitgrowers can now take action if they want to, that is to say, they can then give their first preventive spray, provided their trees are already in the vulnerable stage of development and the grower wants to work preventively. The grower can also wait until the next warning or until the warning that the first ascospore liberation has taken place, but in the first case he runs the risk that he will not have time enough to spray and in the second case he very likely follows a curative scheme and can then wait until infection has taken place.

When we have the first indications that these incubated perithecia have become ripe we take daily a series of leaves directly from the orchard into petridishes in the laboratory. The leaves are wetted and the expulsion of ascospores is observed. When we get ascospores we know that we can expect ascospore liberation in the open as soon as it rains and the second pre-warning (b) is given. There is not always time available for this warning, especially not when it rains immediately after or during this observation.

At the same time we have made ready some small boards with leaves and slides outside in the orchard (fig. 3) just to check the liberation of ascospores under natural conditions.

The boards are covered with filter paper. Six to eight heavily infected leaves are placed upon this cover and fixed by means of small slats. Above each leaf a slide can be fixed between drawing-pins so that they can be changed easily. After each shower they are changed. 


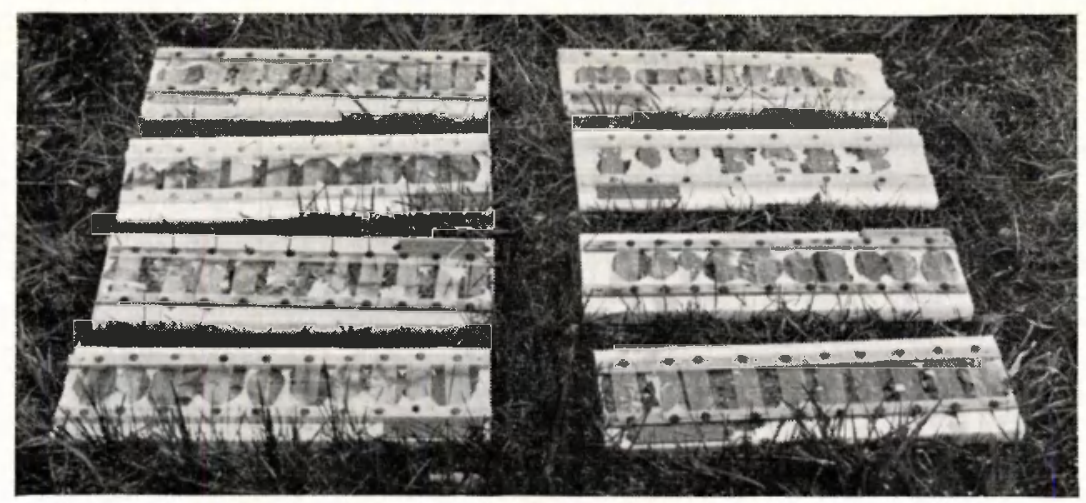

Fig. 3 Boards With INFEcted apple and pear leaves With slides put over them, outSIDE IN THE ORCHARD FOR OBSERVING THE LIBERATION OF ASCOSPORES UNDER NATURAL CONDITIONS.

At the beginning of the ascospore period the boards are taken into the laboratory after rainfall and the slides are examined for the number of ascospores deposited on them. Thus the beginning of ascospore release in the open is determined and can be announced by radio (warning c). With all subsequent rain until the end of the ascospore period ascospore discharge may be expected. Exceptions to this rule can only be expected at the end of a long period of rainfall. They have according to our experience no real significance. After some time these observations are made only incidentally. The numbers of ascospores per leaf are recorded. In this way we learn to know the well sporulating leaves, which we observe then specially for determining the end of the ascospore period. This end is fixed more or less arbitrarily, for the number of ascospores climinishes only very gradually in the course of June and often the beginning of July. The release does not end abrubtly. However, the last few ascospores lose their significance in the dense fruitgrowing centres, where even when one fruitfarm is absolutely free from scab infection about 14 days after the end of the ascospore-period this farm will get infection from the neighbouring orchards.

\section{THE DEVELOPMENT OF THE TREES}

The danger of infection is not only dependent upon the discharge of ascospores, but also upon presence of vulnerable parts of the trees. KEIJER and Dijksterurus (2) have found that apple and pear trees can be infected as soon as any green parts become visible, that is already at early mouse-ear stage (bud burst). The further the bud development the greater is the risk of infection. When there are no green parts there is no need to spray or to warn. The development differs according to the region. So the early warnings have to be given with some regional details. We get a general idea of the development throughout the whole country of the main varieties grown in Holland from data collected by the K.N.M.I. ${ }^{3}$ ). The Agricultural Meteorological

3) Royal Netherlands Meteorological Institute. 
Section of this Institute has - for other purposes - the help of several hundreds of fruitgrowers spread over the country. They regularly send in cards with the stages of the development (according to H.M.S.O. Bulletin 137, London) of the main varieties in their orchard.

The Plant Protection Service gets these data daily by telephone. The name of the variety and the date are put on a small paper flag and the flags are put on maps on the wall (fig. 4). Each stage of tree-development has its own colour. So we can see the entire situation for the whole country at a glance.

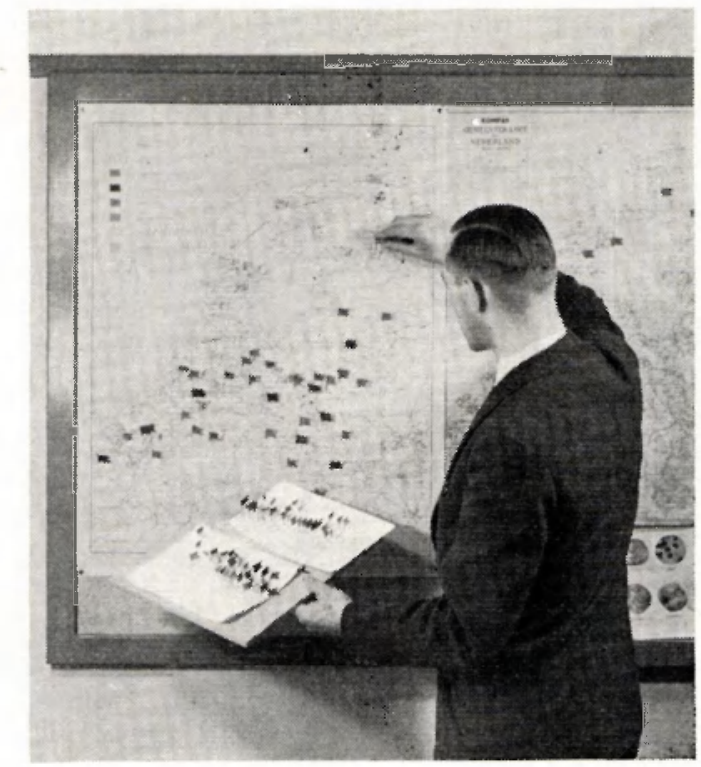

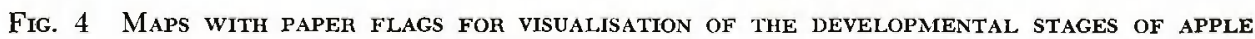
AND PEAR TREES THROUGHOUT THE COUNTRY.

In the same way we are informed about blossoming, which is of importance because of the high susceptibility to damage of the trees shortly afterwards and because of the necessity to avoid spraying trees in full bloom.

The flags for apples are of one colour, those for pears half white, half coloured. We use separate maps for apples and for pears.

\section{THE WEATHER CONDITIONS}

Not every ascospore discharge gives rise to infection. Certain conditions of temperature and of the length of the period of the leaves remaining wet ("the leaf wet period") have to be fulfilled. Some of these data have been selected and put together in a table by MrLus (5). For the determination of these infection periods some instruments are necessary.

A thermograph is needed for recording the temperature during the leafwet period to be able to calculate the mean temperature during leafwetness.

Post (2) has shown that instead of a thermograph a verified max.-min. thermometer, $1_{1 / 2}^{1 /} \mathrm{m}$ above soil level, hung in the shadow, will give sufficiently reliable data provided the sticks have been put on the mercury at the beginning of the rain or as near to that moment as possible. 
The temperature at the beginning and at the end of the leaf wet period has to be noted down as well as the maximum and the minimum temperature during this period. More observations during leaf wetness would be advisable but they are not absolutely necessary. From the sampled temperature readings the mean temperature is taken.

An instrument for recording the leaf wet period would be of great advantage, but up till now none has been available for the radio warning service.

However, in England as well as in Germany and in the Netherlands research is well on its way to find such an instrument. As a help already several types of rainrecorders have been developed (2). One of them is the pluvioscope (Fig. 5 and 6), developed by the K.N.M.I.

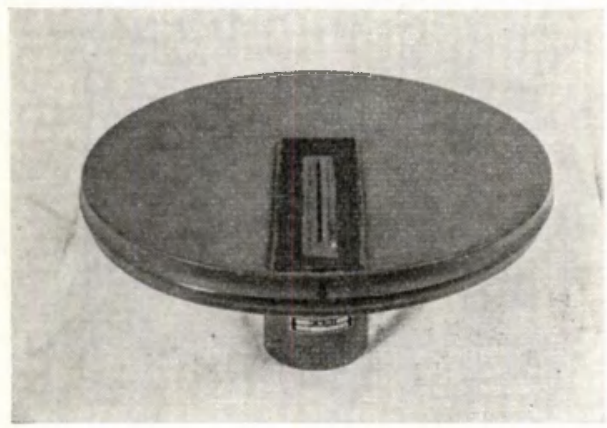

Fic. 5 Plunioscope (RaIN Recorder) in CLOSED POSITION.

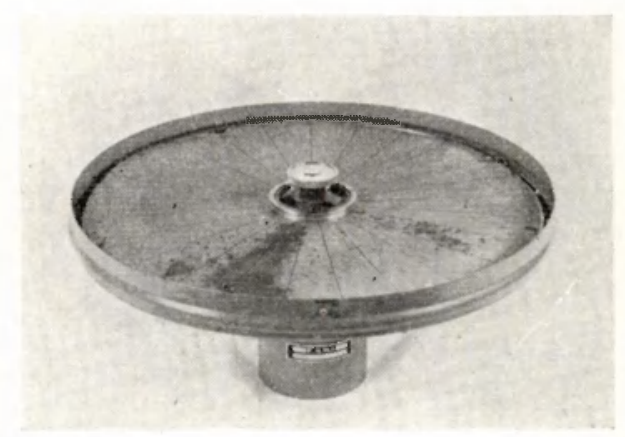

Fig. 6 Pluvioscope OPEned AFter a daY WITH TWO RAIN SHOWERS.

The beginning and the end of the rain period is accurately registered, which is already a great advantage. It saves the necessity of doing observations even during the night and is especially of importance in cases of intermittant rain showers. The data provided by these pluvioscopes have to be supplemented by visual observations to determine the end of the leafwet period. According to our experience one has to consider a tree dry when even the last hidden droplets of water have disappeared.

Most fruitgrowers do not have these instruments. However, since 1954 the Plant Protection Service, together with the K.N.M.I. and since 1956 also with the help of the R.T.V.D. and of several fruitgrowers puts together all available information, determines the infection periods at several points of the country and gives radio messages about these infection periods.

The basic data are nowadays obtained from two sources:

a a number of so-called orchard stations (12 in 1954, 18 in 1957) spread over the country and equipped with instruments (a thermograph, several thermometers and a pluvioscope) from a pool of instruments provided by the K.N.M.I. and the Plant Protection Service;

b the synoptic stations of the K.N.M.I.

All data are phoned to the Plant Protection Service as soon as an infection period has been observed or is to be expected within a few hours. So in principle the initiative to phone is at the orchard stations, which are run by officials of the R.T.V.D., the P.P.S. or by fruitgrowers. The data are collected 


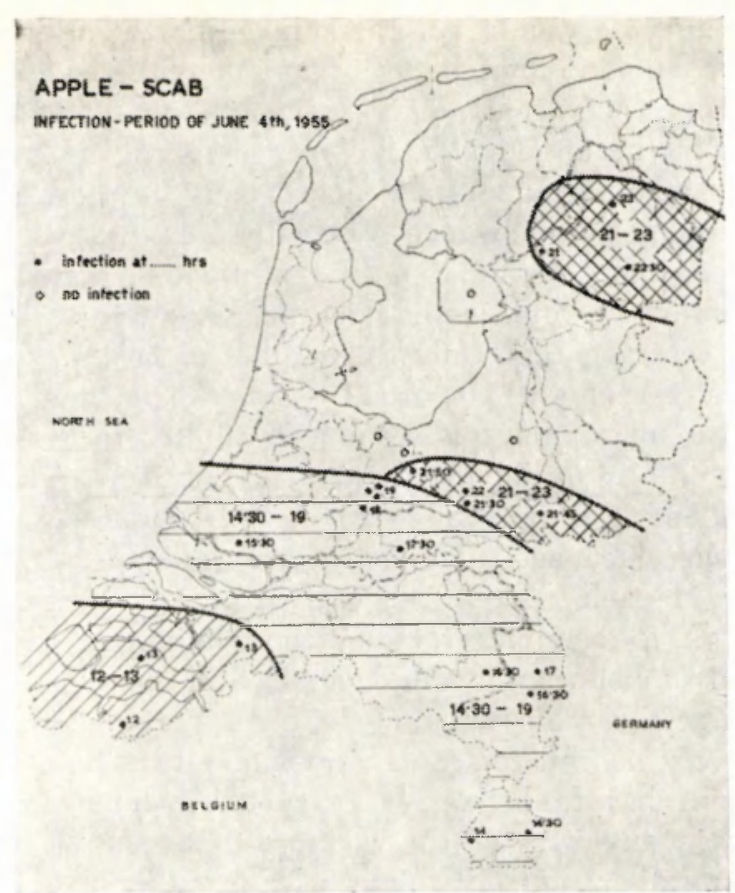

Fig. 7 Map With INfection period of JUne 4Th, 1955.

at the Plant Protection Service. They are plotted on a small map of the Netherlands (Fig. 7) to get an idea of the situation throughout the whole country.

Some initiative has then to be taken by the central point (i.e. the P.P.S.) by phoning to several stations which have not yet reported, to find out what is happening there in time for the weather talks. When we have an idea as to the general position the known facts are put into a short warning, with as many regional details as is possible and necessary. Many growers do start spraying then immediately, even at midnight or on Sundays.

\section{Discussion}

The purpose of the warnings is to give the grower one of the tools he needs for his work. How he wants to use it is up to him. Knowledge about the beginning and the end of ascospore discharge is of importance for every fruitgrower. Knowledge about the infection periods is of different importance for different groups of fruitgrowers. For those who spray only curatively (i.e. after infection has taken place, but before incubation period is over) it is obviously impossible to work without knowing the infection periods. There is another group of growers who work mainly preventively (protectant spraying) but partially curatively. When for some reason or other an infection period is missed a curative spray with organo-mercury compounds will be applied. To allow the use of these for this purpose later in the season the grower should include organo-mercury also in his preventive programme preblossom to avoid the chance of spray damage by using them curatively postblossom. 
When scab is already visible several sprays shortly after each other with fairly aggressive compounds not being organo-mercury have to be applied.

Finally those who want to use only preventive sprays can have advantage of the knowledge of the infection periods for analysing the results of spraying afterwards and to take account of the conclusions the next year.

As it is of the utmost importance especially for curative spraying that no time is lost between the determination of the infection periods and the issuing of the radio warning, it would sometimes be necessary to have more opportunities for radio warning than only three times a day on weekdays. A possibility of giving a warning at about 19.- o'clock in the evening would be of advantage. Also on Sundays a second possibility for this purpose would be necessary, preferably during the night at about 19.- o'clock also.

As will be evident it is impossible to describe precisely in which regions infection has taken place and to give sufficient details about the beginning of the infections in each region. When a rain front passes the situation is often clear enough to compute roughly the reality. In the case of spread rain showers it is much more complicated. Still many fruitgrowers in the Netherlands look at the radio warnings as an important aid. The use of television would be very helpful for explanations about the infection period maps.

Finally the point has to be stressed that the whole system of reporting infection periods in any part of the country to a central point and making radio messages or rather radio warnings of the gathered data only can work when the telephone traffic is quite automatic. Otherwise too much time will be lost by waiting for telephone communications.

\section{ACKNOWLEDGMENTS}

The writer wishes to thank once more Mr. W. C. Moore, C.B.E., M.A., for his kind invitation to read a paper on this subject at the Conference of Advisory Plant Pathologists in Great Britain in 1956. Furthermore he wants to express his sincere thanks to DR. F. JoAN Moore of the Plant Pathology Laboratory at Harpenden (G.B.) for going over the English text.

\section{REFERENCES}

I Commissie voor het Schurftonderzoek bij appel en peer: Het schurftonderzoek in 1952. With a summary: Scab research in 1952. Meded. Dir. Tuinb. 16 (1953) 184-213 and $300-318$.

2 - - : Het schurftonderzoek in 1953 en 1954. With a summary: Apple and pear scab research in 1953 and 1954. Meded. Dir. Tuinb. 18 (1955) 129-151 and 297-324.

3 Gersons, L. et al. : Onderzoek naar de beste tijdstippen der voorjaarsbespuiting tegen appel- en perenschurft II. Tijdschr. o. Plantenz. 48 (1942) 33-60.

4 Knoppien, P. en W. P. N. Vlasveld : Vier jaren voortgezet onderzoek over de schurft van appel en peer. With a summary: Four years of prolonged scab research. Tijdschr. o. Plantenz. 53 (1947) 145-180.

5 Mruls, L. D. and A. A. Laplante: Diseases and insects in the orchard. Cornell Ext. Bull. No. 711 (1951) 21-27.

6 Pol, P. H. VAN DE : Onderzoek naar het beste tijdstip der voorjaarsbespuiting tegen appel- en perenschurft I. Tijdschr. o. Plantenz. 47 (1941) 197-230.

7 Vlasveld, W. P. N.: Het schurftonderzoek in de jaren 1947 en 1948 en de waarnemingen in 1949. With a summary: Investigations and observations on scabdisease in 1947, 1948 and 1949. Tijdschr. o. Plantenz. 56 (1950) 15-32. 